\title{
Analysis of the Factors Constraining the Development of Renewable Energy in Russia
}

\author{
Ruslan Ufa ${ }^{1, a)}$, Alexey Vasilev ${ }^{1, \text { b) }}$ and Yana Malkova ${ }^{1, c)}$ \\ ${ }^{1}$ National Research Tomsk Polytechnic University, 634050 Tomsk, Russia. \\ a)Corresponding author: hecn@tpu.ru \\ b)vasilevas@tpu.ru \\ c)yamalkova96@gmail.com
}

\begin{abstract}
The dynamics of growth and the structure of installed capacity of power plants in the Unified Energy System (UES) of Russia by generation types for 2015-2018 are analyzed. The absolute increase in generating capacity of power plants based on renewable energy sources (RES) is considered, the development prospects and factors constraining the widespread introduction of renewable generation are identified. In particular, the economic factor - renewable energy can not compete with traditional energy resources in the cost of generated electricity, as well as the technical factor associated with solving problems of connecting and operating of RES to the UES of Russia are presented.
\end{abstract}

\section{INTRODUCTION}

In recent years, there is a growing trend in electricity demand, as an individual or industrial consumer, and as the power grid. Predominantly coating increased load is carried out by injection into operation thermal power plants (TPP) [1].

However, along with the rapid growth in the generation of TPP, global environmental problems are becoming more and more evident every year, the emergence of which is associated to the operation of these energy facilities. The hydrocarbon reserves are decreasing and the gap is no more than 150 years, during which it is possible to ensure the growing electricity demand due to implementation of new TPP [2]. Therefore, the issues of re-search and the direct implementation of power plants based of renewable energy sources (RES) are topical.

\section{ANALYSIS OF INSTALLED POWER RES}

The total installed generation capacity of renewable energy sources in Russia has increased significantly, as a result of the annexation of the Crimea, and currently amounts to 594.219 MW solar energy (31 solar power plants) and 139.013 MW wind farms (14 wind power plants) [3], but the level of RES still does not exceed $0.3 \%$ of the total installed capacity, which is $243 \mathrm{GW}$ [1]. In comparison with the leading countries in the employment of renewable energy, this level is very small. Russia occupies 16 th position in the renewable energy distribution rating, in particular in Germany, the share of renewable energy facilities from the total installed capacity is about $48 \%$ (about $98 \mathrm{GW}$ ), and in China $-16 \%$ (about $295 \mathrm{GW}$ ) [3].

In the UES of Russia, facilities on renewable energy sources are presented in five of the seven interconnected power systems (IPS), the leader among which is the IPS of the South, where the total installed capacity of the SPP and WPP is 476.984 MW [3]. The largest power plants on renewable energy sources are Perovo SPP (105.6 MW), Ohotnikovo SPP (82.65 MW), Nikolaevka SPP (69.7 MW), Mityaevo SPP (31.55 MW), Orskaya SPP (40 MW), etc. (Fig. 1). 


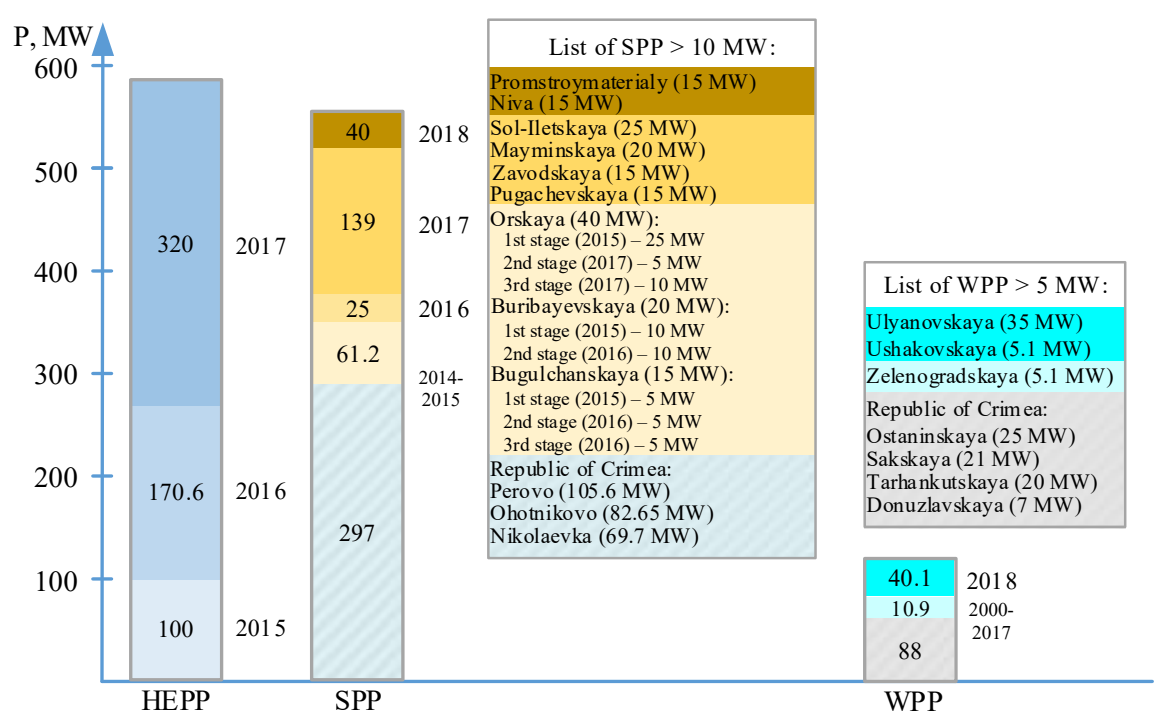

FIGURE 1. Dynamics of growth and structure of installed capacity of power plants based on renewable energy sources of UES of Russia for 2015-2018

However, the large-scale introduction of renewable energy in Russia today is not possible, due to the country's high availability of fossil fuels, subsidizing of traditional energy, lack of interest from the public, business and government in innovations, which, in turn, can be classified as the following factors hindering the development of renewable generation in Russia: economic, regulatory, technical and geographic factors (Fig. 2).

\begin{tabular}{|c|c|c|c|}
\hline \multicolumn{4}{|c|}{ The factors hindering the development of RES } \\
\hline $\begin{array}{l}\text { Economical: } \\
\text {-investments } \\
\text {-localization of } \\
\text { equipment } \\
\text { production }\end{array}$ & $\begin{array}{l}\text { Regulatory: } \\
\text {-standards development } \\
\text {-harmonisation of national } \\
\text { standards } \\
\text {-landing issue }\end{array}$ & $\begin{array}{l}\text { Technical: } \\
\text {-issues of } \\
\text { connection and } \\
\text { operation of } \\
\text { renewable energy } \\
\text { facilities }\end{array}$ & $\begin{array}{l}\text { Geographical: } \\
\text {-limiting the use of } \\
\text { renewable energy due } \\
\text { to environmental } \\
\text { causes }\end{array}$ \\
\hline
\end{tabular}

FIGURE 2. The main factors hindering the development of renewable energy

\section{ANALYSIS TECHNICAL FACTOR}

The task of connecting objects on renewable energy sources to the UES of Russia is not fully resolved to date. Additional research is required to establish the conformity of facilities on renewable energy sources with the cur-rent requirements for generating facilities, namely: power generation and transmission capacity of backbone networks must be sufficient to meet the maximum power demand; electric power systems (EPS) should have sufficient flexibility to solve the problem of generation irregularity and demand uncertainty; EPS should be able to maintain a stable frequency and voltage in the allowable range. In addition, foreign requirements have established that power plants based on RES should remain in operation (be connected to an EPS), maintain the voltage level in various emergency situations - the ability to maintain power supply continuity during disturbances or the ability to maintain power supply continuity at low voltage (Fault Ride-Through or Low Voltage Ride-Through (LVRT) capabilities, respectively).

In Figure 3, if the current voltage in the connection node is LVRT higher than the characteristic, then the generating unit must remain connected to the EPS. Determination of the LVRT characteristics (range of characteristic points) and the corresponding setting of the relay protection require additional studies and calculations that take into account the specifics of the operation of installed power plants based on RES in an EPS. Otherwise, this may cause the disconnection of power plants based on renewable energy sources and the extension of an emergency. 


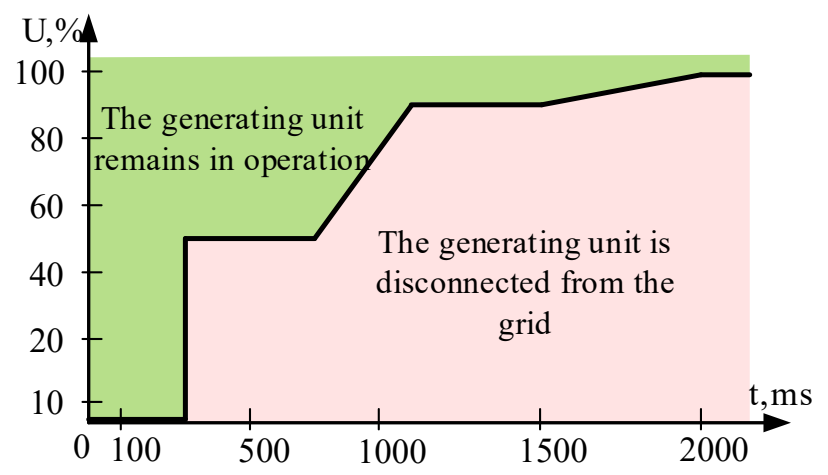

FIGURE 3. Typical LVRT characteristic according to the standard of France

For example, in France (Corsica island) in 2018, the appearance of a three-phase short circuit on the $50 \mathrm{kV}$ grid led to a voltage drop of 50\% and the disconnection of part of the generating equipment of the SPP, which had LVRT function, which did not meet the characteristics of the standard. This example demonstrates the relevance of the task of correct setting and testing of LVRT characteristics [4].

\section{CONCLUSION}

As a result of the analysis of the installed capacity of UES of Russia, an increase in the share of facilities on renewable energy sources was found to be about $0.3 \%$, which is significantly less than the planned $4.5 \%$ reflected in the RF Energy Strategy for the period until 2035 [5]. At the same time, an analysis of the factors hindering the development of renewable energy sources in the UES of Russia showed that this problem is interdisciplinary and its solution requires a set of complementary measures, in particular, economic support from the government and increasing the attractiveness of the industry for private investment, that will help Russia to accumulate experience in the actual operation of these facilities to improve the technology, reduce the cost of producing power and the overall cost of the construction and maintenance of new power plants based on RES.

\section{ACKNOWLEDGMENTS}

The work was supported by Ministry of Science and Higher Education of Russian Federation, according to the research project No MK-2150.2019.9.

\section{REFERENCES}

1. Reports on the functioning of the United Power System, JSC "SO UPS", 2018, see http://soups.ru/index.php?id=ups_reports.

2. C. Zou, Q. Zhao, G. Zhang and B. Xiong, Nat. Gas Ind. 3(1), 1-11 (2016).

3. D. Batarin, A. Barcenin and E. Ryabovol, 50 Gerc. 2-3(30-31), 3-11 (2018).

4. R. A. Jerin, P. Kaliannan and U. Subramaniam, Int. Jour. Amb. Energy. 39(8), 1-7 (2017).

5. Project of the Energy Strategy of the Russian Federation of the period up to 2035, The Ministry of Energy of the Russian Federation, see https://minenergo.gov.ru/node/1920. 